
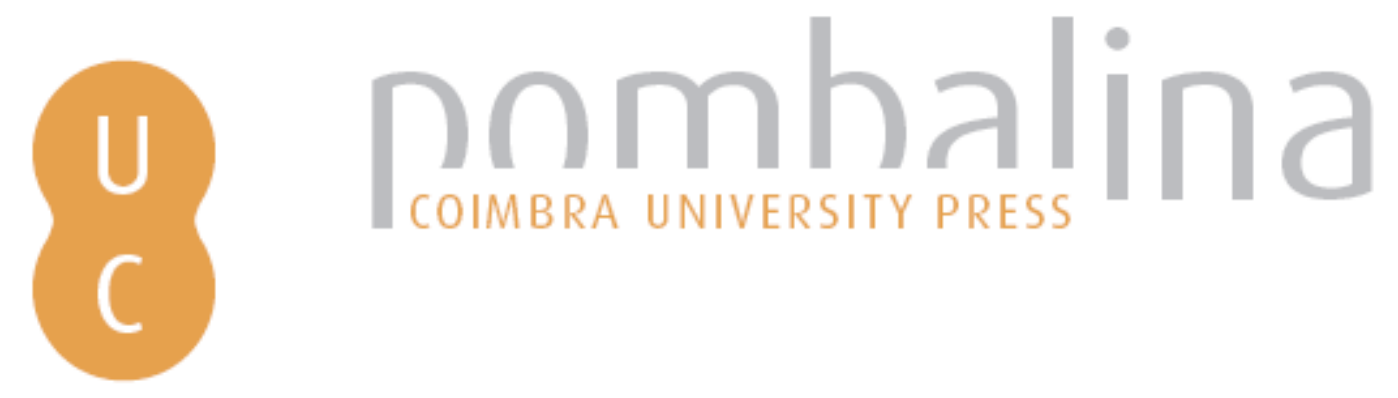

\title{
O espírito olímpico e a importância de aprender Latim no novo milénio
}

\author{
Autor(es): $\quad$ Glücklich, Hans-Joachim \\ Publicado por: Imprensa da Universidade de Coimbra \\ URL \\ persistente: URI:http://hdl.handle.net/10316.2/38363 \\ DOI: $\quad$ DOI:http://dx.doi.org/10.14195/978-989-26-0371-1_1
}

Accessed : $\quad$ 26-Apr-2023 08:21:41

A navegação consulta e descarregamento dos títulos inseridos nas Bibliotecas Digitais UC Digitalis, UC Pombalina e UC Impactum, pressupõem a aceitação plena e sem reservas dos Termos e Condições de Uso destas Bibliotecas Digitais, disponíveis em https://digitalis.uc.pt/pt-pt/termos.

Conforme exposto nos referidos Termos e Condições de Uso, o descarregamento de títulos de acesso restrito requer uma licença válida de autorização devendo o utilizador aceder ao(s) documento(s) a partir de um endereço de IP da instituição detentora da supramencionada licença.

Ao utilizador é apenas permitido o descarregamento para uso pessoal, pelo que o emprego do(s) título(s) descarregado(s) para outro fim, designadamente comercial, carece de autorização do respetivo autor ou editor da obra.

Na medida em que todas as obras da UC Digitalis se encontram protegidas pelo Código do Direito de Autor e Direitos Conexos e demais legislação aplicável, toda a cópia, parcial ou total, deste documento, nos casos em que é legalmente admitida, deverá conter ou fazer-se acompanhar por este aviso.

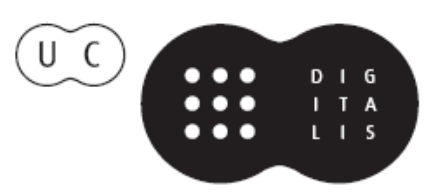


FRANCISCO DE OLIVEIRA

Coordenação

Ospírito Olímpico

no

novo milénio 
O ESPÍRITO OLÍMPICO E A IMPORTÂNCIA

DE APRENDER LATIM NO NOVO MILÉNIO

Hans-Joachim Gl ücklich Universidade de Heidelberg Presidente da Euroclassica

\section{Iudi olympici}

O nosso tema é "0 espírito olímpico no início do novo milénioOs estudiosos da matéria e os jornalistas desportivos modernos são capazes de provar que já na Antiguidade Grega existia o problema do "doping" dos atletas e o da corrupção do júri. Esses aspectos têm algo em comum com os problemas actuais do desporto, da sociedade e dos estilos de vida do nosso tempo. Seria interessante discutir esses aspectos, bem como as razões pelas quais se trata de problemas comuns à antiguidade e aos tempos de hoje. No entanto, uma discussão desse tipo afastar-nos- ia do nosso tema, que é o do espírito olímpico.

É o espírito olímpico que sempre fez e ainda faz dos jogos olímpicos e da ideia olímpica um dos conceitos mais inspiradores da história humana. O espírito olímpico transfere a agressão humana da guerra para a competição, de bellum para certamen. Leva as pessoas da guerra para a paz, ou, pelo menos, para a paz por um certo período de tempo. Impele as pessoas da glória da guerra para a glória da vitória desportiva e proporciona a todos um caminho seguro para a vivência do orgulho nacional. Os Jogos Olímpicos tornaram- se um símbolo da vida humana.

\section{2. certamen: imago vitae}

Desde há muito que se comparam os jogos e concursos físicos e mentais. O estadista e filósofo romano Cícero (Tusculanae disputatio- 
nes, 5, 8-9) conta a história de Pitágoras, que explicava ao líder político Léon o que é um filósofo. Pitágoras distingue três grupos diferentes na sociedade:

1. as pessoas que nascem, vivem e vão aos jogos para alcançar a glória pelas suas virtudes físicas;

2. as pessoas que nascem, vivem e vão aos jogos para ganhar dinheiro;

3. as pessoas que nascem e vão aos jogos para estudar, perceber e discernir as razões e as relações internas.

Embora prefira o terceiro desses grupos, Pitágoras aceita a existência de todos eles e confirma que tanto a vita activa como a vita contemplativa dão sentido à nossa existência, emprestam significado à nossa vida.

Foi também Cícero quem entendeu que o corpo e a mente podem seguir caminhos diferentes e que a vitória nos jogos não significa necessariamente a obtenção de uma personalidade notável. E por esse motivo que, na sua obra De officiis, Cícero procura uma unidade de estilo de vida na qual as acções físicas, mentais e morais se articulam na perfeição. Esse ideal encontrava-se originalmente ligado à ideia do espírito olímpico. O significado da harmonia de um indivíduo pode ser diferente em diferentes épocas. Pindaro descrevia a harmonia de beleza, de virtude, de qualidades sociais e de crenças religiosas existente nos vencedores dos Jogos Olímpicos e louvava, por esse motivo, os jogos e os campeões. Passo a citar um trecho da tradução latina de Philipp Melanchthon, que considerava tanto os Jogos Olímpicos como as Odes de Pindaro como paradigmas da humanidade europeia:

Sed si certamina narrare cupis, o anime, non aliud sole videbis ardentius astrum in die per desertum aethera; neque

Olympico agone praestatiorem alium celebrabimus.

Alma, se queres falar sobre jogos, não verás uma estrela mais brilhante do que o sol no céu durante o dia, nem glorificaremos outro jogo tão excelente como a competição olímpica. 
Nos nossos dias, os atletas olímpicos tentam de novo dar à competição um sentido mais lato e à vitória um significado que transcende o aspecto físico. Lutam, como todos nós, por uma unidade de estilo de vida.

Tentamos encontrar meios que combinem numa só personalidade convincente as diferentes matérias escolares, os diferentes pensamentos, necessidades e desejos que temos. Gostaria de referir que o Latim e o Grego nos poderão ajudar a consegui- lo.

\section{3. memória}

Um desses meios é a memoria. Vitrúvio, o grande arquitecto romano de Augusto, afirma na sua obra Da arquitectura (de architectura, livro 7) que o desenvolvimento da mente humana se deve a muitas pessoas. Só tendo como base aquilo que foi conseguido pelos nossos antecessores seremos capazes de atingir o ponto mais alto do pensamento (pervenirent vetustatibus ad summam doctrinarum subtilitatem). Existem para isso duas condições:

1. A transmissão de pensamentos sob a forma escrita (conscriptio);

2. A memória de pensamentos anteriores (memoria).

Se não falarmos ou escrevermos sobre os nossos pensamentos, tornar-nos-emos culpados de invidia. Não permitimos que os outros conheçam os nossos pensamentos, ficando impossibilitados de construir os seus próprios pensamentos a partir dos nossos. Desse modo, ninguém poderá atingir o ponto supremo do pensamento humano.

Digamos que memoria é a ligação nervosa não apenas num único cérebro e sim na história colectiva da mente. É importante verificarmos como os pensamentos antigos influenciaram durante tantos séculos a mente humana e a história do espírito humano e como ainda exercem a sua influência.

Dependemos desses pensamentos, seja por contacto directo, seja pelo nosso contacto com outros textos, que foram por sua vez influenciados pelos textos clássicos. 
Por exemplo, Cristóvão Colombo, assim como tantos outros, descreveu o continente ocidental recentemente descoberto em termos e de acordo com as perspectivas dos historiadores antigos e dos poetas épicos. Consideravam-se os novos povos como pessoas que careciam de desenvolvimento em termos de cultura e de civilização, sendo o governo espanhol visto como portador da pax Romana. A recusa da aceitação do cristianismo espanhol e do seu governo de paz era entendida como motivo para guerra, como causa iusta para bellum iustum.

Existem inclusivamente comparações entre Colombo e Eneias em várias obras épicas. Os poemas épicos intitulados Columbeis integram a recepção da Eneida de Virgílio.

A própria designação de "América", que provém de Américo Vespucci, era justificada pela comparação com os três nomes, Europa, Ásia e África, e pela ideia de que deveria agora ser um homem o padrinho de um continente.

O desenvolvimento da mente humana não tem início apenas no nosso tempo. Os empreendimentos do nosso tempo, tanto os positivos como os negativos, devem ser vistos sob o pano de fundo da história.

Os Romanos tinham consciência do facto de que deviam muito aos seus predecessores. Escreve Cícero (orator 120):

Desconhecer o que aconteceu antes de termos nascido significa permanecermos crianças toda a vida. A vida dos homens existe apenas se for relacionada com os eventos do passado.

Retirar o Latim e o Grego da educação de base em vez de os tornar obrigatórios em todas as escolas secundárias significa privarmo-nos de todo esse passado histórico, da memoria, de um fundamento apurado dos nossos próprios pensamentos.

\section{4. veritas e identidade}

Esse perigo tem sido identificado por muitos autores. Alguns deles afirmam até que devemos defender a nossa cultura de outras culturas (por exemplo, a cultura islâmica) que revelam uma forte tendência para 
dominar a cultura mundial. Por mim, não iria tão longe, mas gostaria de afirmar que o corte com as nossas raízes comuns significa:

1) obstruir a unificação europeia;

2) entregarmo- nos a uma perda de consciência histórica;

3) rendermo- nos a ditaduras e a ludíbrios.

Vitrúvio (de architectura, livro 7, capítulos 4-7) conta a história de um certamen poetarum, um concurso de poesia que teve lugar em Alexandria. Aristófanes, um membro do júri, foi o único que se apercebeu de que o poeta mais apreciado cometia plágio. Isto demonstra que memoria significa muito mais do que uma obrigação moral de honrar os tempos passados. Memoria constitui, por si mesma, uma qualidade moral, uma vez que é uma fonte de juízo e de opinião independentes. Independência não significa espontaneidade e loquacidade, e sim a discussão crítica de pensamentos anteriores e ainda mais a capacidade de pôr em questão e de discutir as tendências actuais do pensamento e dos modos de vida, confrontando- os com outras possibilidades.

Os ditadores têm os seus motivos para ou promover a ausência e a perda da consciência histórica, ou permitir apenas uma consciência e um conhecimento seleccionados.

Na sua obra Fahrenheit 451 (a temperatura a partir da qual o papel começa a arder), Ray Bradbury mostra, tal como o faz François Truffaut no seu filme homónimo, como um ditador quer queimar todos os livros a fim de atingir esse objectivo de provocar uma perda cultural e conseguir assim uma manipulação total da mente humana.

Hoje em dia, os ditadores modernos são a cultura de massas, o culto do proletário em vez de cultura, um certo tipo de turismo e o entretenimento total.

\section{5. homo expeditus}

Quais são as condições para se ser um jurado competente e independente? Segundo Vitruvius (de architectura 7,5), o jurado independente Aristófanes foi eleito porque lia todos os livros com o máximo empenho 
possível (summo studio), e a máxima precisão e atenção possíveis (summa diligentia).

Isso tornava-o expeditus. Expeditus é o oposto de impeditus, o resultado de um longo processo de educação que liberta alguém de trechos desnecessários do seu caminho, não se perturbando com a tendência ou a opinião públicas. É alguém capaz de comparar o novo e o velho com rapidez e independência, com um rápido acesso à história e às fontes, com um espírito bem treinado e uma inteligência aperfeiçoada. Analisa as novas ideias e processos com rapidez e independência.

\section{6. lingua}

\section{a) ratio - oratio}

E essa independência que exige também o conhecimento do Latim e, pelo menos, algum conhecimento do Grego. Todas as traduções são interpretações, todas as traduções dependem do tradutor e do seu tempo.

Cícero mostra (de officiis 1,12 e 50-51) como a combinação da linguagem e do pensamento forma a rede mundial da humanidade:

Com o poder da ratio, a natureza racional liga a humanidade a uma sociedade de ratio e de oratio, de ratio e de fala $(1,12)$. (...) E essa a maior conexão social dos homens (I, 50- 51).

A linguagem revela a forma como pensamos e, não havendo conhecimento do Latim, não há efectivamente acesso aos pensamentos dos tempos antigos. Assim, não é suficiente aceitar que estamos ligados aos pensamentos de épocas anteriores, mas temos também que aceitar que esses pensamentos não podem ser lidos e discutidos de forma independente se não tivermos conhecimento do Latim e do Grego.

Para além desta, muitas outras razões se podem invocar para provar a importância do conhecimento da língua latina. 


\section{b) forma}

A beleza e a estrutura da língua latina clássica são reconhecidas por quase todos, mesmo por aqueles que não concordam com o seu ensino nas escolas.

Lion Feuchtwanger regista no seu diário o que lhe disse o poeta alemão Bertolt Brecht: "Mesmo se Horácio exprime os pensamentos mais triviais, tudo soa maravilhoso, pois ele trabalhou com mármore e nós trabalhamos com porcaria." E Feuchtewanger explica ainda que "Bertolt Brecht usou uma palavra mais ordinária".

Contudo, forma significa também disciplina. Os autores latinos clássicos são bem conhecidos pela capacidade de adequar conteúdos e estrutura nas suas frases, enchendo- as de impressões sonoras e visuais, o que não surpreende num mundo em que se lia alto e em que não existiam a fotografia e a televisão. Assim, todas essas funções cabiam à linguagem.

\section{c) verba}

O Latim é a chamada língua- mãe de quase todas as línguas europeias. Saber Latim facilita a aprendizagem do vocabulário de outras línguas. Torna mais fácil também a compreensão do sentido e do próprio "ambiente" das palavras.

\section{d) syntaxis et grammatica}

Os nossos métodos de ensino completo da gramática ajudam também a entender mais facilmente a estrutura de outras línguas. Em nossa opinião, a gramática é uma chave para a compreensão do pensamento das pessoas e da mente das pessoas.

Esta afirmação leva-me a acrescentar que há que ter cuidado em não se treinar a gramática sem discutir e apreciar os conteúdos de um dado texto. A gramática só é convincente e inspiradora se formos capazes de mostrar o significado da gramática e da linguagem na expressão e nos efeitos que pretendemos obter. Uma vez que o Latim é, hoje em dia, uma língua maioritariamente escrita e não falada, podemos 
concentrar-nos na estrutura, na terminologia, na comparação com outras línguas.

\section{e) linguagem científica e palavras estrangeiras}

A linguagem científica é ainda hoje dominada pelo Latim e pelo Grego e, embora se encontrem mais palavras inglesas, muitas delas são de origem latina ou grega, tal como "copy" (cópia), "computer" (computador), "initialize" (inicializar), "memory" (memória). A língua inglesa mais cuidada, especialmente as palavras que designam conceitos abstractos, as palavras da ciência, da política, da história e da filosofia são de origem franco-normanda, o que significa, em última análise, que têm uma origem latina, por exemplo "to believe" (acreditar) é um termo originalmente anglo-germânico, mas a maioria das palavras relacionadas com "crença" deriva da palavra latina credere: creed (credo): sistema de crença religiosa; to credit (acreditar, dar crédito): crer, confiar; credit (crédito): acreditar que alguém vai poder pagar dívidas ou cumprir uma promessa; (in)credible (in-crível): em que (não) se pode acreditar; credulous (crédulo): que acredita com demasiada facilidade.

\section{Europa}

Numa carta que escreveu ao filho, que viria a ser Filipe II, o rei de Espanha Carlos IV fala- Ihe de alguns princípios da educação: "Como vos disse em Madrid, não penseis que é infantil estudar". O estudo ajudou a fazer o homem. Ser um homem não era uma questão de corpo, mas sim de espírito e só o estudo poderia consegui-lo. E sobretudo, o príncipe iria governar muitos países de línguas diferentes e era essencial saber

14 Latim para comunicar com todos eles. "Nem seria demais se soubésseis um pouco de Francês". É óbvio que o rei D. Carlos considerava ser o Latim a mais importante língua de comunicação europeia e o Francês a segunda em importância.

Hoje em dia provavelmente recomendaria o Inglês. O Inglês é a língua franca do hemisfério ocidental, embora a maioria das pessoas incluindo eu - fale um Inglês mais ou menos mau. A sua amplitude vai do 
Inglês de Inglaterra até ao da América, ao Australiano, desde o Inglês propriamente dito ao Inglês "miscigenado", passando pelo Inglês comercial, até ao Inglês formal dos académicos.

Haverá, no entanto, uma razão que justifique o conhecer-se um pouco de Latim? Andréas Alfóldy, um historiador da Universidade de Heidelberg, compara a organização supranacional do Império Romano e a Comunidade Europeia e verifica que a administração romana funcionava eficazmente, concedendo direitos políticos a todos os membros do Imperium e utilizando esse facto como meio de integração de muitos grupos étnicos diferentes. Prova também o mesmo autor que não era através das medidas económicas que se obtinha a integração, mas sim através de medidas culturais, tais como a expansão generalizada da cultura greco-romana, que se tornou a base do pensamento, da cultura e da educação europeias.

Alfóldy exige uma integração cultural muito mais intensa dos países europeus porque a economia não é nem o único caminho conducente à integração, nem será um caminho completo. Aquele historiador encontra a ligação unificadora nas raízes comuns da língua e da cultura latinas, que - como mostrámos atrás - influenciam o tempo presente não apenas directamente, mas também através de toda uma série de obras-primas da cultura que foram criadas na Europa, influenciadas pela antiguidade e pelos escritores e artistas Gregos e Romanos.

Combinados com os argumentos linguísticos já apresentados, estes factos apontam fortemente para a importância de uma nova vaga de ensino do Latim e também do Grego nas escolas secundárias em toda a Comunidade Europeia.

\section{EUA}

Mesmo nos Estados Unidos, alguns professores, académicos e outras pessoas ligadas ao sistema educativo já tomaram consciência da importância da aprendizagem do Latim.

O Latim ajuda a entender as palavras estrangeiras e a linguagem científica. Mas ajuda também a melhorar o conhecimento do sentido das palavras e a competência ortográfica. A escrita das chamadas palavras 
difíceis (de origem grega e latina) torna-se mais fácil, por exemplo: "exam" (exame), debt (dívida). Pode entender-se o humor das palavras "abreviadas", como por exemplo: "prof ' (professor), "fab" (fabuloso), ab ("fab abs": abdominais fabulosos). E pode até perceber-se o chamado "ProfTalk" ("Professorês"), por exemplo:

"Professorês": "A sua estrutura afectiva de desvalores leva- o a conclusões essencialistas."

Linguagem Simples: "Esse gajo é um chato."

"Professorês": "Generalize o documento."

Linguagem Simples: "Faça 25 cópias e distribua"

Contudo, os americanos fazem o mesmo que uma série de países europeus e tentam construir a sua história independentemente das respectivas raízes. Os EUA pretendem ser independentes da Europa, mas dependem da cultura europeia e do sistema político europeu. Foram influenciados pelo modo como os conquistadores europeus viam e tratavam os povos nativos da América. A Pax Romana e a Pax Americana têm algo em comum.

Os fundadores da nação americana promoveram a educação clássica. A Constituição americana e a Declaração de Independência encontram as suas raízes nos pensamentos de Cícero sobre o direito natural, e os pensamentos de Lincoln, Jefferson, Franklin e Madison devem muito a Roma e à Grécia.

No entanto, mesmo nessa época era negada a influência do pensamento romano. A história dos Estados Unidos levou a maior parte dos autores políticos a crer que a democracia americana seria muito diferente do sistema parlamentar inglês. O inglês Thomas Paine, bem como os americanos Jefferson e Madison, entendiam que o governo representativo ou o sistema representativo era "uma invenção do mundo moderno". Na opinião de Jefferson, tinha-se tornado inútil quase tudo quanto fora escrito antes do sistema americano sobre a estrutura dos governos. E Paine afirmava: "O que Atenas foi em miniatura, a América será em magnitude." Queria dizer: uma democracia. No entanto, tal comparação e tal identificação da democracia antiga e da moderna, da democracia ateniense e da democracia americana não são 
correctas. A nova democracia representativa não é uma constituição sem misturas de monarca, aristocratas e povo - e o novo sistema americano teria que ser uma constituição pura. James Madison concebeu a ideia da democracia representativa com base na Europa, revelando conhecer a sua origem histórica. Mas mesmo Madison pensava que "a América pode reclamar os louros de ter descoberto repúblicas puras e amplas."

\section{9. conclusão}

Não temos nenhum motivo para negarmos as nossas raízes. Por isso, poderei terminar em jeito de provocação e de uma forma optimista: o conhecimento do Latim e do Grego, bem como da literatura clássica e das suas recepções, ajudam-nos a evitar seguirmos apenas o nosso ponto de vista e o nosso próprio modo de ajuizar. Queremos evitar ser como uma ditadura e adoptar uma forma de pensar totalitária. A tendência para tornarmos absoluto o nosso próprio ponto de vista é humana e pode ser detectada nos curricula das democracias modernas. Estas deveriam acolher com agrado o contributo que uma educação clássica traz ao desenvolvimento de um modo de pensar liberal e independente. $O$ ensino do Latim e do Grego ajuda a ajuizar de forma independente, a tornarmo- nos conscientes das nossas raízes comuns e, ao mesmo tempo, a entendermos as nossas raízes nacionais. É por essas razões que gostaria de afirmar que o conhecimento do Latim e do Grego ensina a compreensão do presente. $E$, nessa medida, o exemplo do espírito Olímpico e o regresso dos jogos Olímpicos deverão animar e encorajar todos quantos são responsáveis pela educação e pela política a promover o Latim e o Grego. 


\section{Bibliografia}

G. Alföldy, Das Imperium Romanum - ein Vorbild für das vereinte Europa? "Jacob Burckhardt — Gespräche auf Castelen. Heft 9. Schwabe Verlag, Basel 1999

J. Blänsdorf, Das Naturrecht in der Verfassung. Von Ciceros Staatstheorie zum modernen Naturrechtsdenken, in: H.-J. Glücklich (ed.): Lateinische Literatur, heute wirkend, vol. II, Göttingen 1987, pp. 30-59

A. Fritsch, Latein im dritten Jahrtausend. "Historische" Kommunikation als Lernziel des Lateinunterrichts", in: Latein und Griechisch in Berlin und Brandenburg 44/ 1, 2000, pp. 2- 16

H. - J. Glücklich: Herkunft braucht Zukunft. Der Lateinunterricht heute und morgen, in: Gymnasium 104/6, 1997, pp. 481- 508

H. Hofmann: Die Geburt Americas aus dem Geist der Antike, in: International Journal of the Classical Tradition 1/4, 1995, pp. 15/47

Henry Kamen, Philip of Spain, Yale University Press New Haven and London 1997

D. Sternberger: Die neue Politie. Vorschläge zu einer Revision der Lehre vom Verfassunsstaat, in: Jahrbuch des öffentlichen Rechts der Gegenwart, NF Bd. 33, Tübingen 1984, pp. 1- 40

\section{I. Fontes}

\section{Cicero, Tusculanae disputationes, book 5, § 9:}

Pythagoram autem respondisse similem sibi videri vitam hominum et mercatum eum, qui haberetur maxumo ludorum apparatu totius Graeciae celebritate; nam ut illic alii corporibus exercitatis gloriam et nobilitatem coronae peterent, alii emendi aut vendendi quaestu et lucro ducerentur, esset autem quoddam genus eorum, idque vel maxime ingenuum, qui nec plausum nec lucrum quaererent, sed visendi causa venirent studioseque perspicerent, quid ageretur et quo modo, item nos quasi in mercatus quandam celebritatem ex urbe aliqua sic in hanc vitam ex alia vita et natura profectos alios gloriae servire, alios pecuniae, raros esse quosdam, qui ceteris omnibus pro nihilo habitis rerum naturam studiose intuerentur; hos se appellare sapientiae studiosos - id est enim philosophos; et ut illic liberalissimum esset spectare nihil sibi adquirentem, sic in vita longe omnibus studiis contemplationem rerum cognitionemque praestare.

Vitruv, de architectura, liber 7 :

(I) Maiores cum sapienter tum etiam utiliter instituerunt, per commentariorum relationes cogitata tradere posteris, ut ea non interirent, sed singulis aetatibus crescentia voluminibus edita gradatim pervenirent vetustatibus ad summam doctrinarum subtilitatem. Itaque non 
mediocres, sed infinitae sunt his agendae gratiae, quod non invidiose silentes praetermiserunt, sed omnium generum sensus conscriptionibus memoriae tradendos curaverunt.

(3) Itaque quemadmodum his gratiae sunt agendae, contra, qui eorum scripta furantes pro suis praedicant, sunt vituperandi, quique non propriis cogitationibus scriptorum nituntur, sed invidis moribus aliena violantes gloriantur, non modo sunt reprehendendi, sed etiam, quia impio more vixerunt, poena condemnandi. Nec tamen hae res non vindicatae curiosius ab antiquis esse memorantur. Quorum exitus iudiciorum qui fuerint, non est alienum, quemadmodum sint nobis traditi, explicare.

(5) His ita institutis, cum ludi adessent, iudices litterati, qui ea probarent, erant legendi. Rex, cum iam sex civitatis lectos habuisset nec tam cito septumum idoneum inveniret, retulit ad eos, qui supra bybliothecam fuerunt, et quaesiit, si quem novissent ad it expeditum. Tunc ei dixerunt esse quendam Aristophanen, qui summo studio summaque diligentia cotidie omnes libros ex ordine perlegeret. Itaque conventu ludorum, cum secretae sedes iudicibus essent distributae, cum ceteris Aristophanes citatus, quemadmodum fuerat locus ei designatus, sedit.

\section{Cicero, Orator 120:}

Nescire autem, quid, ante quam natus sis, acciderit, id est semper esse puerum. Quid enim est aetas hominis, nisi ea memoria rerum veterum cum superiorum aetate contexitur? Commemoratio autem antiquitatis exemplorumque prolatio summa cum delectatione et auctoritatem orationi affert et fidem.

\section{Cicero, de officiis 1,12 :}

Eademque natura vi rationis hominem conciliat homini et ad orationis et ad vitae societatem...

Cicero, de officiis $1,50-5 \mathrm{I}$ :

Sed quae naturae principia sint communitatis et societatis humanae, repetendum videtur altius. Est enim primum quod cernitur in universi generis humani societate. Eius autem vinculum est ratio et oratio, quae docendo, discendo, communicando, disceptando, iudicando conciliat inter se homines coniungitque naturali quadam societate, neque ulla re longius absumus a natura ferarum, in quibus inesse fortitudinem saepe dicimus, ut in equis, in leonibus, iustitiam, aequitatem, bonitatem non dicimus; sunt enim rationis et orationis expertes. Ac latissime quidem patens hominibus inter ipsos, omnibus inter omnes societas haec est.

\section{Melanchthon's Translation of Pindar's First Olympian Ode:}

(Pindari Thebani Lyricorum veterum principis. Olympia. Pythia. Nemea. Isthmia. Per Philippum Melanchthonem latinitati donata, nunc primum in lucem edita. Basileae. Oporinus 1558) 
(Strophe I)

Optima res est aqua. Aurum excellit in superbis divitiis, sicut excellit fulvus ignis nocte. Sed si certamina narrare cupis, o anime, non aliud sole videbis ardentius astrum in die per desertum aethera; neque Olympico agone praestantiorem alium celebrabimus. Unde celeberrimus hymnus oritur sapientum cogitationibus, ut celebrent lovem, euntes ad divitem domum Hieronis,

\section{(Antistrophe I)}

qui tenet iustum regnum in divite Sicilia, decerpens ex singulis virtutibus cacumen. Laetatur et musices flore, ut viros saepe in conviviis ludere videmus. Sed Doricam citharam prehendito a clavo, si tibi Pisae et equi victoris iucunditas movit mentem ad dulces cogitationes: quando ad Alpheum incitavit equi corpus sine flagellis, et cursu dominum fecit victorem,

\section{(Epodos I)}

regem Syracusium, equis gaudentem. Lucet eius gloria apud Lydii Pelopis coloniam, quem Neptunus amavit, postquam ex lebete eum Clotho extraxit, ornatum humero eburneo. Mirum est, quod saepe hominum mentes decipiunt fabulae fabricatae mendaciis. Cupio verum sermonem.

\section{(Str. 2)}

Sed Gratia, quae facit omnia iucunda hominibus, adfert honorem, et facit, ut credantur incredibilia.Sed futurum tempus retegit mendacia. Decet Minor enim culpa est. Fili Tantali, ego te laudabo aliter quam priores. Quando vocavit Deos pater ad legitimas epulas, et ad Sipylum, ut vicissim daret Diis cenam: tunc Neptunum

\section{(Ant.2)}

desiderio tui flagratem, aio te rapuisse in aureo curru, ad summam lovis domum, quo et postea Ganymedes venit lovi ad idem ministerium. Postquam vero non conspectus es, nec te ad matrem reduxerunt illi, qui te quaesiverunt, dixit aliquis clam ex invidis vicinis, quod in aqua fervente gladio membra dissecuissent; et in mensis minutas carnes tuas distribuissent et comedissent.

(Ep.2)

Mihi vero absurdum est, dicere, aliquem Deorum esse heluonem, quia damnum comitatur crebo maledicos. $\mathrm{Si}$ quem hominem Dii honoraverunt, fuit hic Tantalus. Sed concoquere magnam felicitatem non potuit. Saturitate accepit magnum damnum, ut lupiter ei supra caput suspenderit lapidem, quem semper cogitans delapsurum esse in caput aberrat a laetitia.

\section{(Str. 3)}

Habet autem miseram vitam et aerumnosam, cum tribus quartum laborem: cum Ixione implicito rotae, cum Tityo, qui roditur a vulture, quod furatus rosum dedit aequalibus suis convivis nectar et ambrosiam, in quibus rebus Dii immortalitatem posuerunt Pelopem ad homines, cui ad florentem aetatem, cum lanugo nigrum ei mentum coronabat, curavit paratas nuptias,

(Ant.3)

ut haberet inclytam Hippodamiam, filiam Oenomai, regis Pisae. Noctu autem solus ad mare accedens, vocabat Neptunum, qui mox apparuit ei. Dixit autem Pelops: Si tibi hoc coniugium placet, impedias hastam Oenomai aeneam, meque in curru celerrimo ducas ad Heliden, et mihi dato victoriam, postquam tredecim procis interfectis, differt nuptias. 
(ep.3)

Res periculosa postulat virum non timidum. Cum autem alioquin necesse sit mori, cur aliquis sedens in tenebris, obscura senecta, maceretur, gloriae expers? Ego certamen aggredior, tu praebeto gratum eventum. Sic dicit Pelops, nec irrita fuit petitio, ac laetificans Deus Pelopem dedit ei currum aureum et indefessos equos.

\section{(Str.4)}

Cepit igitur validum Oenomaum et virginem coniugem, quae peperit sex filios, principes virtutem curantes. Nunc inter sepultos iacet, ad Alpheum, apud aram frequentissimam, et adspicit celebritatem Olympicorum certaminum, ubi velocitas pedum certat, et vigor roboris. Victor autem postea in mellita tranquillitate vivit,
(Ant 4)

propter victoriae praemiae. Sic semper id bonum summum dicitur, quod illo die contigit, quo fructum percepimus superiorum laborum. Me vero coronare victorem equestri lege Aeolico carmine oportet. Confido enim neminem posse me laudare alium magis excellentem scientia honestarum rerum et potentia eorum, qui nunc sunt, quam Hieronem. Deus custos, conservans tuam gloriam, curat tuas sollicitudines. Hic si me non cito destituet, spero me dulciori

(Ep. 4)

carmine te celebraturum esse, cum in curru celeri accedam ad lovis templum, inventa materia. Mihi Musa telum praebet validissimum. Alii aliis rebus excellunt. Summum vero decus est regnum. Ne maiora appetas. Contingat tibi in tota vita excallere; mihi vero, familiarem esse victoribus, conspicuo per Graeciam propter sapientiam. 